\title{
Lab-scale ash production by abrasion and collision experiments of porous volcanic samples
}

\author{
Sebastian B. Mueller (1), Steve J. Lane (1), and Ulrich Kueppers (2) \\ (1) Lancaster Environment Centre, Lancaster University, Lancaster, UK, (2) Earth \& Environmental Sciences, \\ Ludwig-Maximilians-University (LMU), Munich, Germany
}

In the course of explosive eruptions, magma is fragmented into smaller pieces by a plethora of processes before deposition. Volcanic ash, all fragments smaller than $2 \mathrm{~mm}$, may have imminent and near-volcano effects but may also cause various problems over long duration and/or far away from the source. In an attempt to quantify the efficiency of ash generation, various experimental setups were applied on pumice and scoria samples. We used samples collected on Tenerife (Canary Islands, Spain), Sicily and Lipari Islands (both Italy) for experiments that generated shear or normal stress fields or combinations of these within the rock samples. Experiments were designed to overcome low yield strengths of samples and produce ash, with this study having particular interest in the $<355 \mu \mathrm{m}$ fraction. By abrasion and collision experiments, the processes that are likely to happen within volcanic conduits, plumes or pyroclastic density currents (PDCs) were simulated. An understanding of these secondary fragmentation processes is crucial as they are capable of producing very fine ash, with size ranges from a few microns to few millimetres. These particles are known to remain in the atmosphere for several days and travel large distances $(\sim$ $100 \mathrm{~s}$ of $\mathrm{km}$ ). This poses threats to the aviation industry and human health. From the experiments we establish that abrasion setups produced the finest material and up to $50 \%$ of the generated ash was smaller than $10 \mu \mathrm{m}$. In comparison, the drop experiments that applied mainly normal stress fields produced coarser grain sizes. Results were compared to grain size distributions described in literature for natural fall and PDC deposits and good correlation was found. Energies involved in drop experiments were calculated and showed an exponential correlation with ash production rate. Projecting these results into the actual volcanic environment, highest amounts of ash are produced in most energetic and turbulent areas, which are proximal to the vent. Finest grain sizes are produced in PDCs and can be observed as co-ignimbrite clouds above density currents. Finally, a significant dependency of particle size distribution and amount of fines produced on material density was found: lower rock density supports particle failure and produces both finer and more material. This study is based on numerous previous studies on particle comminution processes; however it is the first to analyse and compare results of several comminution experiments with each other. 